\title{
In vitro anti-proliferative effects of Zuojinwan on eight kinds of human cancer cell lines
}

\author{
Lina Xu $\cdot$ Yan Qi $\cdot$ Linlin Lv $\cdot$ Youwei Xu • \\ Lingli Zheng $\cdot$ Lianhong Yin $\cdot$ Kexin Liu $\cdot$ \\ Xu Han $\cdot$ Yanyan Zhao $\cdot$ Jinyong Peng
}

Received: 29 October 2012/ Accepted: 2 January 2013/Published online: 9 February 2013

(C) Springer Science+Business Media Dordrecht 2013

\begin{abstract}
Zuojinwan (ZJW), a famous Chinese medicinal formula, contains two medicinal herbs Coptis chinese Frach and Evodia rutaecarpa (Juss.) Benth in the ratio of 6: 1 . The inhibitory effects of $Z J W$ on eight kinds of human cancer cell lines including SMMC7721, BEL-7402, BEL-7404, HepG2, A549, NCIH446, NCI-H460 and HCT- 116 cells were evaluated, and the possible mechanism was investigated. The growths of the eight kinds of cancer cells were inhibited by $Z J W$ assessed through MTT assay. Flow cytometry assay revealed a sub-G1 peak with reduced DNA content was formed. The cell cycle was arrested in the G0/G1 phase in ZJW-treated SMMC-7721 and HepG2 cells, and in the S phase for NCI-H460 cells. Significant DNA damage was produced by ZJW assessed with single-cell gel electrophoresis assay. Morphological changes were also observed. Caspase- 3 and -9 activities were increased following $Z J W$ treatment. Western blot
\end{abstract}

The authors L. Xu and Y. Qi contribute same work to this work and they are the co-first authors.

L. Xu $\cdot$ Y. Qi $\cdot$ L. Lv $\cdot$ Y. Xu $\cdot$ L. Yin

K. Liu $\cdot$ X. Han $\cdot$ Y. Zhao $\cdot$ J. Peng $(\bowtie)$

College of Pharmacy, Dalian Medical University,

9 Western Lvshun South Road, Dalian 116044, China

e-mail: jinyongpeng2010@yahoo.cn

L. Zheng $(\bowtie)$

The First Affiliated Hospital, Dalian Medical University,

Dalian 116011, China

e-mail: zheng_112009@126.com analysis showed that Bax and Bak protein levels were increased after $Z J W$ treatment, while Bcl-2 and Bcl-xl protein levels were decreased. Our results suggest that $Z J W$ has significant anti-cancer activities due to induction of mitochondria- dependent apoptosis pathway. Therefore, $Z J W$ has the potential to be a novel chemotherapy drug to treat hepatoma, lung cancer and colon cancer by suppressing tumor growth.

Keywords Apoptosis - Caspase · Cell cycle · Mitochondrial pathway $\cdot$ Zuojinwan

\section{Introduction}

In nowadays, malignant cancers are amongst the most important cause of mortality worldwide. Among them, lung cancer, hepatic carcinoma and colorectal cancer are more malignant with high morbidity and mortality (Jemal et al. 2008; Wang et al. 2010; Lu et al. 2010b; Danhier et al. 2010). However, most available chemotherapies can cause severe side effects due to toxicity of non-cancerous tissue, and often become inefficient due to chemoresistance (Can and Aydiner 2011; Kekre et al. 2005). Therefore, there is an urgent quest for investigation of more efficient antitumor agents with low toxic effects.

The pathogenesis of cancer is very complex, and the therapeutic effects of a single chemical may be modest and hampered by various side effects or resistances to drugs in clinics. In some Southeast Asian countries, 
extensive experience and abundant data on the treatment of cancers with traditional Chinese medicines (TCMs) have been documented (Zhang and Zhang 2008; Hu et al. 2009). It is believed that formulae combined with multiple herbs under the guidance of theories of TCM could hit multiple targets and reduce the adverse effects (Wang et al. 2012; Pedro et al. 2007).

Zuojinwan $(Z J W)$, a famous traditional Chinese medical formulation, was first described in a famous ancient medicine treatise Danxi Xinfa written hundreds of years ago. $Z J W$ is composed of two kinds of medicinal plants, Coptis chinese Frach and Evodia rutaecarpa (Juss.) Benth in the ratio of 6: $1(\mathrm{w} / \mathrm{w})$, and it has been listed in the Chinese Pharmacopoeia. The main activity compounds in $Z J W$ are considered to be alkaloids including berberine, coptisine, jateorhizine, palmatine and epiberberine from $C$. Chinese Frach, and evodiamine and rutaecarpine from E. rutaecarpa (Juss.) Benth (Sheng et al. 2006; Yang et al. 2009; Gao et al. 2010). Pharmacological results have indicated that $Z J W$ has the activites of anti-inflammation, anti-ulcer and anti-acid activities and inhibitory effect on the growth of Helicobacter pylori (Chen et al. 2003). Nowadays, ZJW has been applied to treated hepatitis, cholecystitis, peptic ulcer and other kinds of gastrointestinal diseases in the clinical practice (Cheng et al. 2011).

In recent years, extensive attention has been drawn to some major compounds of $Z J W$ with regard to the anticancer effects (Tang et al. 2009; Jantova et al. 2007; Kang et al. 2005; Pan et al. 2012). Our previous studies (Wang et al. 2008; Wang et al. 2009) have shown that berberine and evodiamine have synergistic inhibitory effects on SMMGC-7721 cells, and ZJW is more powerful than C. Chinese Frach and E. rutaecarpa (Juss.) Benth in growth inhibition of S180 tumor in vivo when singly used. $Z J W$ and its constituents, berberine and evodiamine, could suppress tumor promotion primarily through AP-1 and/or NF- $\mathrm{kB}$ pathways as identified in HepG2 cells (Chao et al. 2011). However, the inhibitory effects of this integrate formula on other cancer cell lines have not yet been studied, and the molecular anti-cancer mechanism of $Z J W$ was not fully elucidated.

Accordingly, for the high morbidity and mortality, human hepatocellular carcinoma cells (SMMC-7721, BEL-7402, BEL-7404 and HepG2), human lung cancer cells (A549, NCI-H446 and NCI-H460) and human colon cancer cells (HCT-116) were chosen in the present study to investigate the cytotoxic effect of $Z J W$ and elucidate the possible mechanisms.
The results indicate that activity of $Z J W$ in inducing apoptosis of these cancer cells corresponds to activate the mitochondrial pathways. $Z J W$ should be a valuable candidate anti-tumor agent.

\section{Materials and methods}

Reagents

RPMI-1640 medium (RPMI-1640), minimum essential medium (MEM) and Dulbecco's modified Eagle medium (DMEM) were purchased from Gibico/BRL Invitrogen (Gaithersburg, MD, USA). Acridine orange (AO), ethidium bromide (EB), DAPI (4',6-diamidino2-phenylindole), Rhodamine 123 (Rh123) and 3-(4,5-dimethylthiazol-2-yl)-2,5-diphenyltetrazolium bromide (MTT) were provided by Sigma (St. Louis, MO, USA). Caspase-3 and Caspase-9 Activity Assay kits, cell cycle and apoptosis analysis kit, cell lysis buffer for western blotting and intracellular proteolysis (IP) were all purchased from Beyotime Institute of Biotechnology (Nanjing, China). C. Chinese Frach and E. rutaecarpa (Juss.) Benth were purchased from a local drug store (Dalian, China) and identified by Dr. Yunpeng Diao (Dalian Medical University, Dalian, China). Voucher specimens were deposited at the College of Pharmacy, Dalian Medical University (Dalian, China). Vinorelbine with the purity of $>98 \%$ used as the positive control was obtained from Shanghai Touto Biotech Co. Ltd (Shanghai, China).

\section{Preparation of ZJW}

The preparation of $Z J W$ was performed following the method as described previously (Wang et al. 2009). C. Chinese Frach (18 g) and E. rutaecarpa (Juss.) Benth ( $3 \mathrm{~g})$ were weighed and extracted with water reflux extraction method ( $210 \mathrm{ml}$ water, two times) for $2 \mathrm{~h}$. The extract was evaporated using a rotary vacuum-evaporator at $50{ }^{\circ} \mathrm{C}$. The dried extract was then weighed and reconstituted with $10 \%$ DMSO to prepare a stock solution at a concentration of $10 \mathrm{mg} /$ $\mathrm{ml}$. The stock solution was serially diluted to different working concentrations. In order to control the quality of $Z J W$ extract, the concentration of berberine in ZJW extract was determined by high performance liquid chromatography (HPLC) according to the Chinese Pharmacopoeia 2010 (Ch.P2010). 
Cell lines and culture

Human hepatocellular carcinoma cells (SMMC-7721, BEL-7402, BEL-7404 and HepG2), human lung cancer cells (A549, NCI-H446 and NCI-H460) and human colon cancer cells (HCT-116) were obtained from the Shanghai Cell Biology Institute of Chinese Academy of Science (Shanghai, China). The cells were maintained in RPMI 1640 (SMMC-7721, BEL7402, BEL-7404 and HCT-116), MEM (HepG2) or DMEM (A549, NCI-H446 and NCI-H460) supplemented with $10 \%$ fetal calf serum (FBS, Invitrogen Corp., Carlsbad, CA, USA), penicillin (100 U/ml) and streptomycin $(100 \mu \mathrm{g} / \mathrm{ml})$. Cultivation was conducted under $100 \%$ humidity and $5 \% \mathrm{CO}_{2}$ at $37{ }^{\circ} \mathrm{C}$. Cell passages were performed every 4-5 days and the cells were refed every 2 days. In the experiments (see below), cells were cultured in 96-, 24- or 6-well plates, and they were allowed to adhere and grow for $24 \mathrm{~h}$ in culture medium prior to supplemented with $Z J W$.

Inhibition effect of ZJW on cancer cells

SMMC-7721, BEL-7402, BEL-7404, HepG2, A549, NCI-H446, NCI-H460 and HCT-116 cells $\left(1 \times 10^{5}\right.$ cells $\left./ \mathrm{ml}\right)$ were seeded in $100 \mu \mathrm{l}$ of medium/well in 96-well plates, respectively. After incubation overnight, different concentrations of ZJW (19, $38,76,152$ and $304 \mu \mathrm{g} / \mathrm{ml}$ ) or the vehicle (DMSO, $0.3 \%)$ were added at various concentrations. The un-treated cells were used as control. After being incubated with $Z J W$ for 24,48 , and $72 \mathrm{~h}$, cell viabilities were analyzed by MTT test (Sigma, St. Louis, MO, USA) with an ELISA Micro-plate Reader at $570 \mathrm{~nm}$ filter and the inhibition ratios were calculated.

\section{Cell cycle analysis}

To determine the cell cycle, $1 \times 10^{6}$ cells/well were seeded in 6-well cell culture plates and treated with $Z J W$ at a final concentration of 38,76 and $152 \mu \mathrm{g} / \mathrm{ml}$. After $24 \mathrm{~h}$ treatment, both floating and trypsinized adherent cells were collected and fixed with $70 \%$ ethanol. After fixation, the cells were washed with PBS and stained with propidium iodide (PI) for $20 \mathrm{~min}$ under subdued light. Stained cells were analyzed using FACScalibur and CellQuest software (BD Bioscience, San Jose, CA, USA).
Single cell gel electrophoresis (SCGE) assay

All kinds of cancer cells were seeded in 6-well cell culture plates and treated with $Z J W(152 \mu \mathrm{g} / \mathrm{ml})$ for $24 \mathrm{~h}$ as described above. The single cell gel electrophoresis (SCGE) assay (comet assay) was performed under alkaline conditions as per the manufacturer's instructions (Cell Biolabs, Inc, SanDiego, CA, USA). Images of the cells were obtained using a fluorescence microscope (OLYMPUS CORPORATION, Tokyo, Japan). At least 150 randomly selected cells (50 cells from each of the three replicate slides) were analyzed per sample with the Comet Assay Software Project (CASP) 1.2.2.

\section{AO/EB fluorescent staining}

Cancer cells were plated in 24-well plates and treated with $Z J W$ at a final concentration of 38,76 and $152 \mu \mathrm{g} /$ ml. Cells without $Z J W$ served as control. After 24, 48 or $72 \mathrm{~h}$ treatment, $10 \mu \mathrm{l}$ of the $\mathrm{AO} / \mathrm{EB}$ dye mix $(100 \mu \mathrm{g} / \mathrm{ml}$ of $\mathrm{AO}$ and $100 \mu \mathrm{g} / \mathrm{ml}$ of EB in PBS) were added to each well. The apoptotic, necrotic and live cells were observed and counted under the fluorescent microscope (CKX41, OLYMPUS).

\section{DAPI assay}

The assay was performed on all kinds of the cancer cells treated with different concentration of $Z J W$ (38, 76 and $152 \mu \mathrm{g} / \mathrm{ml}$ ) in 24-well plates. After $24 \mathrm{~h}$ treatment, cells were washed with cold PBS following fixation in $2 \%$ paraformaldehyde at room temperature for $30 \mathrm{~min}$. Then the cells were washed twice with PBS, and maintained in PBS containing $0.1 \%$ Triton $\mathrm{X}-100$ at room temperature for another $30 \mathrm{~min}$. Cells were subsequently incubated in DAPI $(1 \mu \mathrm{g} / \mathrm{ml})$ solution at room temperature for $30 \mathrm{~min}$, washed with PBS and examined under a fluorescence microscope (CKX41, OLYMPUS).

\section{Rhodamine123 assay}

Rhodamine123 (Rh123) is a fluorescent cationic dye that binds to polarized mitochondrial membrane and accumulates as aggregates in the mitochondria of normal cells. After treatment with ZJW (38, 76 and $152 \mu \mathrm{g} / \mathrm{ml}$ ) for $24 \mathrm{~h}$, the final concentration of $5 \mu \mathrm{g} / \mathrm{ml}$ of Rh123 in PBS was added and cultures 
were incubated at $37^{\circ} \mathrm{C}$ for $60 \mathrm{~min}$ in 6-well plates. After washing with PBS, the images of cells after uptake and retention of Rh123 were analyzed by fluorescence microscopy (CKX41, OLYMPUS).

Ultramicrostructure observation

SMMC-7721, A549 and HCT-116 cells were chosen to evaluate the ultramicrostructure changes caused by $Z J W$. Briefly, adherent cancer cells were treated with $Z J W(152 \mu \mathrm{g} / \mathrm{ml})$ for $24 \mathrm{~h}$ in the 6-well plates. After treatment, the treated cells were digested with pancreatin and fixed with $3 \%$ glutaraldehyde overnight. The cells were washed by $0.1 \mathrm{M}$ phosphate buffer and fixed in $2 \%$ osmium tetroxied for $2 \mathrm{~h}$. Then, the specimens were dehydrated by acetone and embedded by epoxide resin (Dai et al. 2009). After staining with uranyl acetate and lead citrate, the sections were observed under a transmission electron microscope (JEM-2000EX, JEOL Ltd, Tokyo, Japan).

Caspase-3 and -9 activities assay

SMMC-7721, A549 and HCT-116 cells were collected after incubation with $Z J W$ at the concentrations of 38, 76 and $152 \mu \mathrm{g} / \mathrm{ml}$ for $24 \mathrm{~h}$. The activities of Caspase- 3 and -9 were detected according to the instructions of the Caspase3 and -9 Activity Assay kits. Briefly, the mixture of $80 \mu \mathrm{l}$ detection buffer, $10 \mu \mathrm{l}$ sample, $10 \mu \mathrm{l}$ Ac-DEVD- $p$ NA or Ac-IETD- $p$ NA was incubated at $37^{\circ} \mathrm{C}$ for $2 \mathrm{~h}$, and then the $\mathrm{OD}_{405}$ was measured. The activities of Caspase- 3 and -9 were calculated based on a standard curve.

\section{Protein extraction and western blotting}

To investigate the anticancer mechanism of $Z J W$, SMMC-7721, A549 and HCT-116 cells were chosen for western blotting analysis. Total protein was isolated using protein extraction kit based on the manufacturer's instructions (Beyotime Institute of Biotechnology, Nantong, China) after SMMC-7721, A549 and HCT-116 cells have been incubated with $Z J W$ at the concentrations of 38,76 and $152 \mu \mathrm{g} / \mathrm{ml}$ for $24 \mathrm{~h}$. The protein concentrations were determined using the BCA assay (Beyotime Institute of Biotechnology, Nantong, China). Equal amounts of protein samples were loaded onto a sodium dodecyl sulphatepolyacrylamide gel electrophoresis (SDS-PAGE). The gels were transferred to polyvinylidene fluoride
(PVDF) membranes (Millipore, USA) before immunodetection processing with anti- GAPDH, anti-Bax, anti-Bak, anti-Bcl-2 and anti-Bcl-xl antibodies (Santa Cruz Biotechnology, Santa Cruz, CA, USA), and with secondary antibodies (peroxidase conjugated antimouse or anti-rabbit $\mathrm{IgG}$ ). Immunodetection was performed using ECL-plus reagents (Beyotime Institute of Biotechnology) and photographed by BioSpectrumGel Imaging System (UVP, LLC, Upland, CA, USA) (Lu et al. 2010a, b). To eliminate the variations, the data were adjusted to GAPDH expression (IOD of objective protein VS IOD of GAPDH protein).

\section{Statistical analysis}

All data were expressed as mean \pm SD. Statistical analysis was performed using the SPSS 11.0 for Windows. ANOVA (one-way analysis of variance) was used to analyze statistical differences between groups under different conditions. $P$ value $<0.05$ was considered statistically significant.

\section{Results}

Inhibition effects of ZJW on cancer cell lines

The effects of $Z J W$ on the proliferations of SMMC7721, BEL-7402, BEL-7404, HepG2, A549, NCIH446, NCI-H460 and HCT-116 cells were determined by MTT assay. Cells were treated with different concentrations of $Z J W$ under different treatment times. From the results, we can see that the addition of DMSO (highest concentration was $0.3 \%$ ) in cell cultures did not affect the proliferation of all these cells. The highest inhibitory effects of $Z J W$ on SMMC-7721, BEL-7402, BEL- 7404, HepG2, A549, NCI-H446, NCI-H460 and HCT-116 cells reached $85.15,76.94,87.32,64.25,54.77,61.72,54.70$ and $78.45 \%$ at $72 \mathrm{~h}$, respectively. According to the inhibitory rates, a dose-dependent manner of $Z J W$ was observed in all kinds of the tested cell lines (Fig. 1). Thus, 38, 76 and $152 \mu \mathrm{g} / \mathrm{ml}$ of $Z J W$ were selected for subsequent investigations.

ZJW affects the cell cycle of cancer cell lines

To investigate the effects of $Z J W$ on cell cycle progression in SMMC-7721, BEL-7402, BEL-7404, 

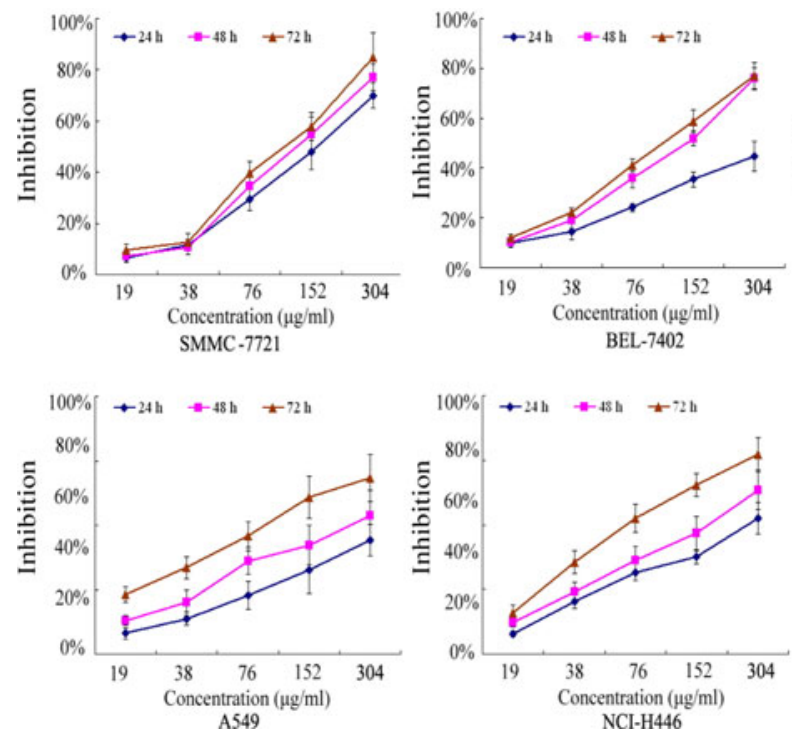

Fig. 1 Inhibitory effects of $Z J W$ on eight kinds of cancer cell lines. The inhibitory effects detected by MTT test were dosedependent $(0,19,38,76,152$ and $304 \mathrm{ZJW} \mu \mathrm{g} / \mathrm{ml})$ at different

HepG2, A549, NCI-H446, NCI-H460 and HCT-116 cells, we measured the DNA content of cancer cells treated with 38,76 and $152 \mu \mathrm{g} / \mathrm{ml} \mathrm{ZJW}$ using a flow cytometer. The representative diagrams are shown in Fig. 2. Cells treated with $Z J W$ for $24 \mathrm{~h}$ exhibited a typical sub-G1 fraction which represented the apoptotic cell population. For SMMC-7721 cells, the proportion of G0/G1 phase increased from $42.29 \%$ to $92.00 \%$ when the cancer cells were treated with $152 \mu \mathrm{g} / \mathrm{ml} \mathrm{ZJW}$ for $24 \mathrm{~h}$, which revealed that $Z J W$ could cause a G0/G1 arrest in SMMC-7721 cells. HepG2 cells in G0/G1 phase increased from $59.55 \%$ to $68.61 \%$, which demonstrated a G0/G1 phase arrest caused by ZJW. The population of NCI-H460 cells significantly decreased from $62.41 \%$ to $45.28 \%$ in G0/G1 phase and increased from $29.59 \%$ to $47.94 \%$ in $S$ phase when the cells were treated with $152 \mu \mathrm{g} / \mathrm{ml}$ $Z J W$. These results indicated a significant $\mathrm{S}$ phase arrest effects of $Z J W$ on NCI-H460 cells. For the other kinds of cancer cells, no significant cell cycle arrest effects were detected.

\section{ZJW causes DNA damage of cancer cells}

SCGE assay was used to determine the effect of ZJW on nuclear DNA damage. As shown in Fig. 3, the comet appeared mostly as a single circular shape in control cells. This represented the majority of long-
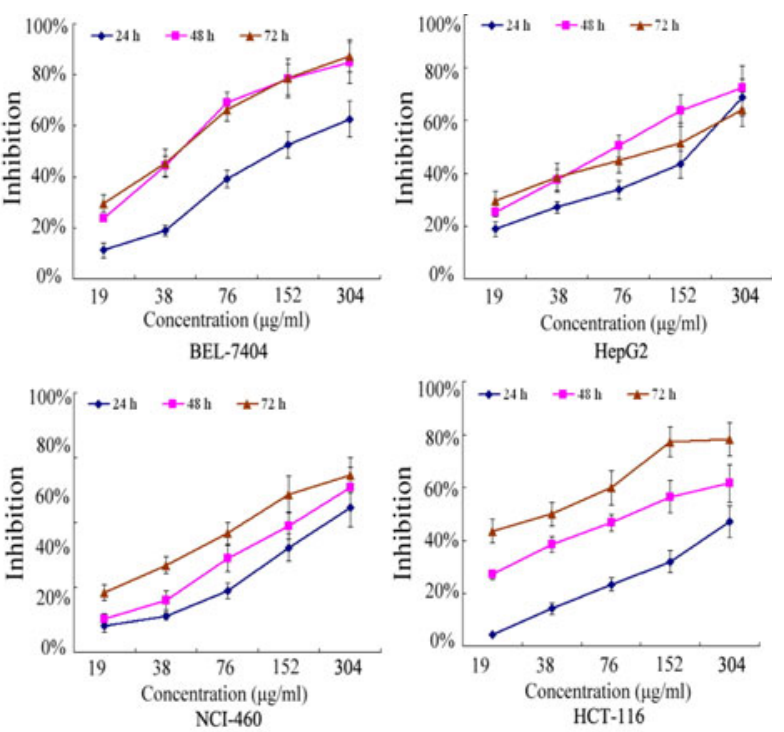

treatment times $(24,48$ and $72 \mathrm{~h})$. Each value is expressed as mean \pm SEM of three independent experiments

stranded DNA remaining in the nucleus of the cell, with very little fragmentation. An increase in the length and density of the comet-tail was seen in $Z J W$ treated cells, representing a decrease in fragment size and an increase in the number of fragmented pieces of DNA. At the same time, the nucleus was seen to decrease in size and density, due to the loss of longstranded DNA by fragmentation.

The effects of ZJW on morphological and ultrastructural changes

$\mathrm{AO} / \mathrm{EB}$ double fluorescent staining was carried out to observe apoptotic morphology of the cancer cells. As shown in Fig. 4, after AO/EB staining, cells exposed to $Z J W$ revealed marked nuclear condensation, membrane blebbing, nuclear fragmentation and apoptotic bodies, all of which are the characteristics of apoptotic programmed cell death.

Morphological changes on all kinds of cancer cells induced by $Z J W$ were also observed using DAPI staining. The changes that occurred in the cells as a result of $Z J W$ treatment are shown in Fig. 5. After DAPI staining, all kinds of cancer cells exposed to $Z J W$ revealed marked nuclear fragmentation and chromatin condensation which were clear indications of apoptosis. No such effects were observed in untreated cells. 

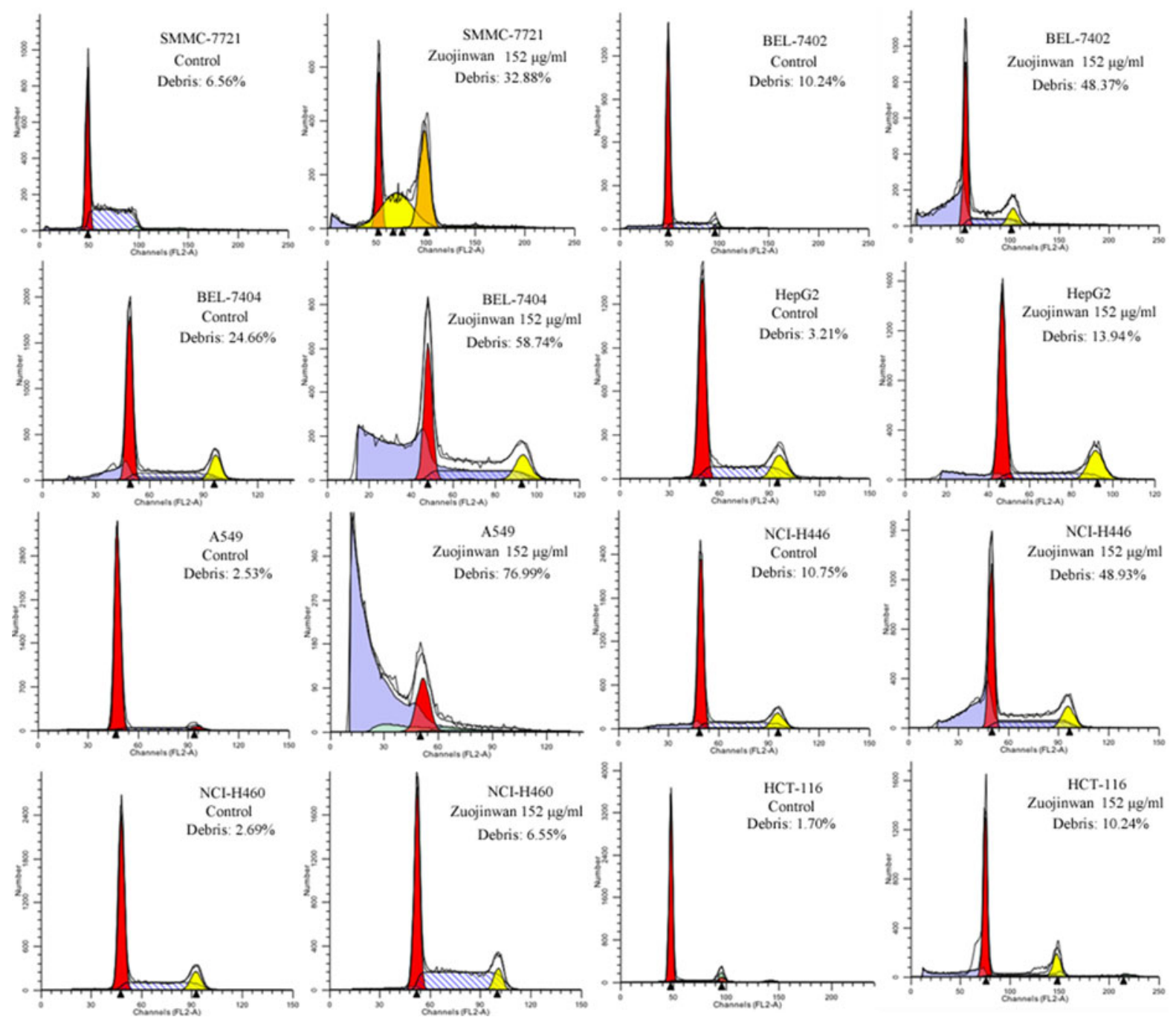

Fig. 2 Effects of $Z J W$ on cell cycle arrest in each cancer cell line detected by flow cytometry

To assess the relationship between the apoptosis induced by $Z J W$ and mitochondrial membrane permeability transition, the cells were stained with $\mathrm{Rh}$ 123. As shown in Fig. 6, the fluorescence of stained mitochondria markedly diminished in the cells exposed to $Z J W$, suggesting that the cells lost their mitochondrial inner membrane potential.

TEM was used to confirm apoptosis in SMMC7721 , A549 and HCT-116 cells treated with $Z J W$ in this study. It is shown in Fig. 7 that the cancer cells treated with $Z J W$ for $24 \mathrm{~h}$ produced some major morphological alterations, including the disappearance of mitochondrial cristae, nuclear condensation and membrane blebbing. All these morphological characteristics are the properties of the apoptotic cells, indicating that apoptosis played a crucial role in cell death elicited by ZJW on SMMC-7721, A549 and HCT-116 cells.

ZJW increases the activities of Caspase-3 and -9

As shown in Fig. 8, ZJW significantly $(p<0.05)$ enhanced both Caspase- 3 and -9 activities and a dosedependent manner was observed. After SMMC-7721, A549 and HCT-116 cells were treated with $152 \mu \mathrm{g} / \mathrm{ml}$ of $Z J W$ for $24 \mathrm{~h}$, the activities of Caspase-3 were increased about 2.14, 1.90 and 2.29 fold $(p<0.01)$, and the activities of Caspase- 9 were increased about 1.87, 1.91 and 2.04 fold compared to those before treatment, respectively. This concluded that $Z J W$ 
Control

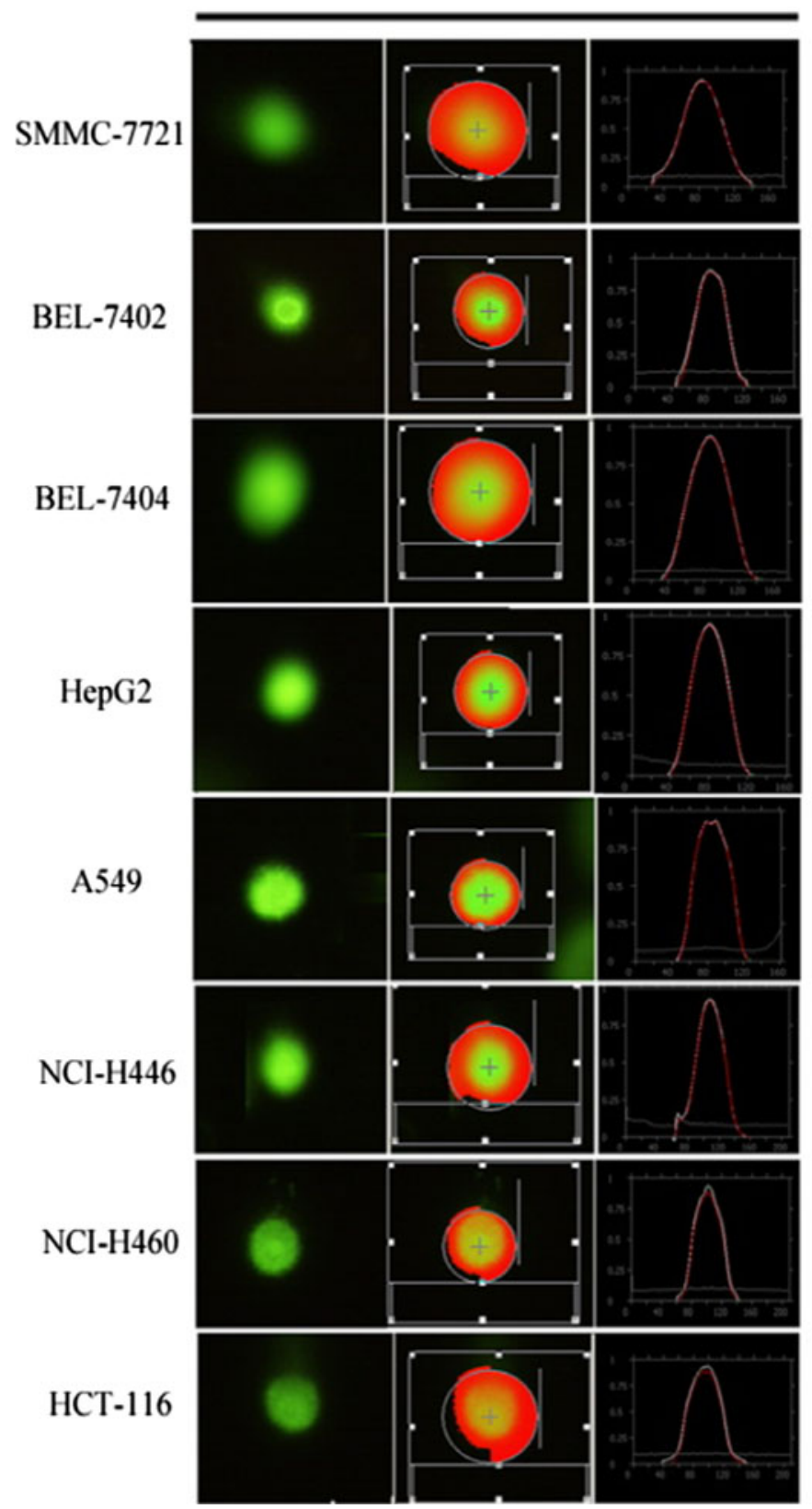

Zuojinwan $152 \mu \mathrm{g} / \mathrm{ml}$
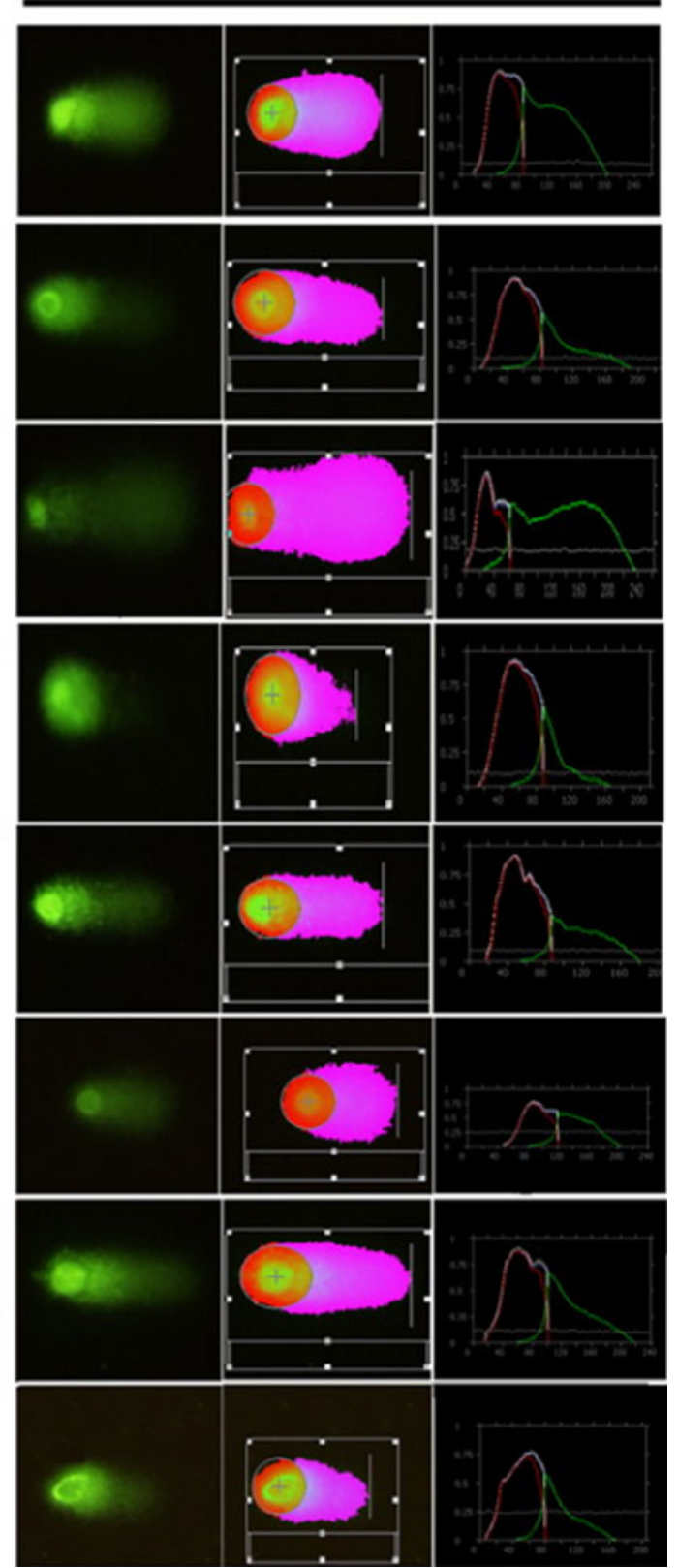

Fig. 3 DNA damage of the eight kinds of cell lines induced by $152 \mu \mathrm{g} / \mathrm{ml} Z J W$ for $24 \mathrm{~h}$ assessed by the comet assay

induced apoptosis through the intrinsic mitochondrial pathway.

ZJW activates Bcl-2 family members

The expression of the pro-apoptotic proteins Bax and Bak, and anti-apoptotic proteins Bcl-2 and Bcl-xl were investigated by western blotting. As seen in Fig. 9, the expressions of Bax and Bak were consistently upregulated to 2.23, 5.50, 2.86 times and 3.05, 10.45, 3.50 times in SMMC-7721, A549 and HCT-116 cells, respectively ( $p<0.01$ ). On the other hand, the protein levels of Bcl-2 and Bcl-xl were significantly decreased in a dose-dependent manner when cancer cells were 


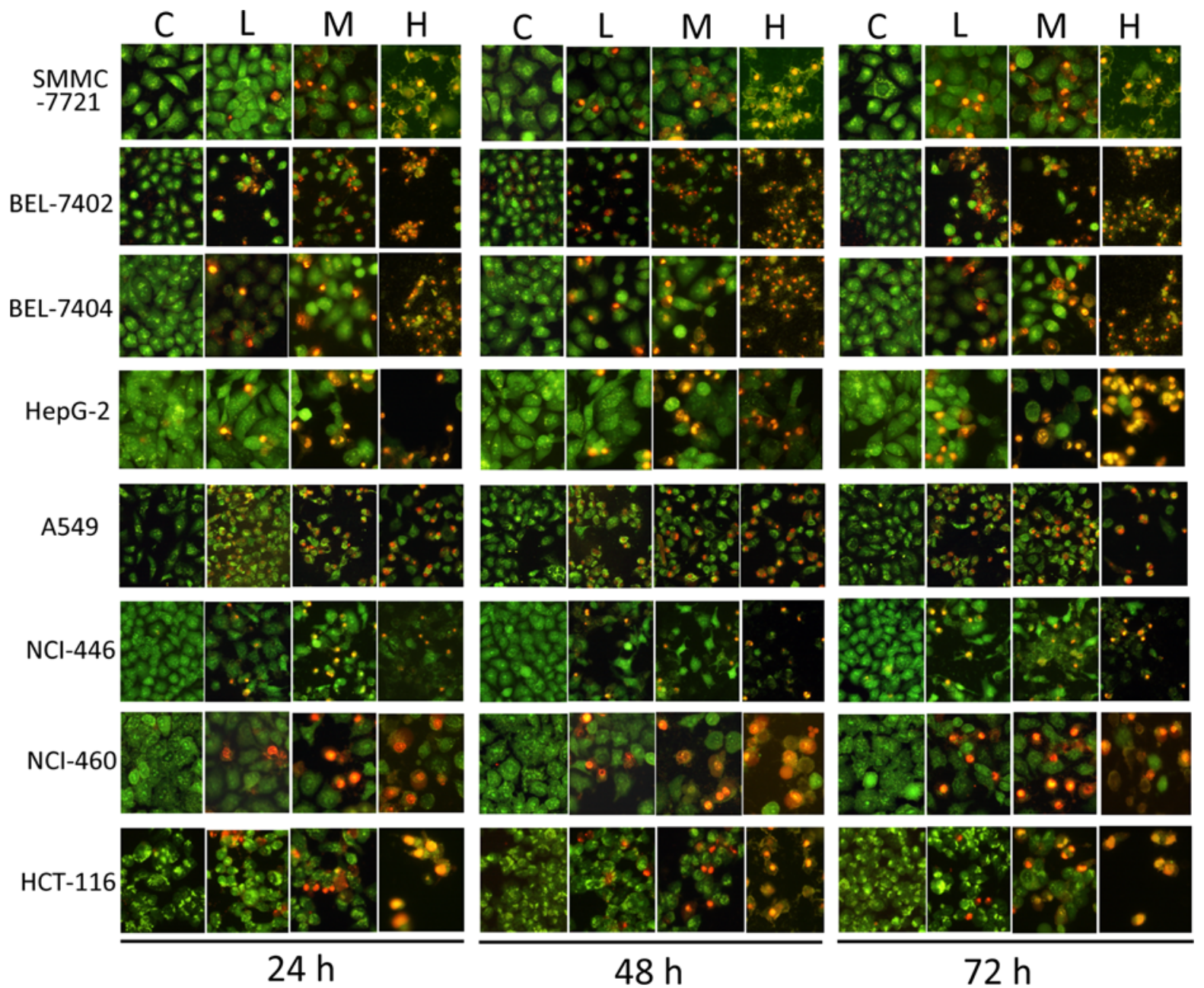

Fig. $4 \mathrm{AO} / \mathrm{EB}$ double fluorescent staining of the cancer cells treated with different concentrations of $Z J W$ for 24,48 and 72 h. C: control; L: $38 \mu \mathrm{g} / \mathrm{ml} Z J W$; M: $76 \mu \mathrm{g} / \mathrm{ml} Z J W$; H: $152 \mu \mathrm{g} / \mathrm{ml} Z J W$

treated with $Z J W$ for $24 \mathrm{~h}$. The expressions of Bcl-2 and Bcl-xl were down-regulated to $18.75,47.17$, $21.80 \%$ and $25.74,30.70,7.82 \%$, respectively, in comparison to untreated SMMC-7721, A549 and HCT-116 cells $(p<0.01)$.

\section{Discussion}

Apoptosis, which plays an important role in the development and tissue homeostasis, is a major form of cell death characterized by series of tightly regulated processes that involve the activation of a cascade leading to death (Boleti et al. 2008). In this process, morphological changes can be observed, including cytoplasm shrinkage, chromatin condensation, plasma membrane blebs, DNA damage and apoptotic body formation (Suresh et al. 2011). In order to detect the cell apoptosis induced by $Z J W$, changes in cell growth, cell cycle, DNA damage and morphology in human hepatocellular carcinoma cells (SMMC-7721, BEL-7402, BEL-7404 and HepG2), human lung cancer cells (A549, NCI-H446 and NCI-H460) and human colon cancer cells (HCT-116) were investigated.

In order to choose suitable concentrations of $Z J W$, different concentrations of $Z J W$ extract were optimized according to the paper by Chao et al. (2011). The inhibitory effect of $Z J W$ at a concentration of $152 \mu \mathrm{g} / \mathrm{ml}$ did not reach $50 \%$ for some cancer cell lines, whereas these effects were beyond $50 \%$ for other cell lines. Thus for the subsequent experiments, 


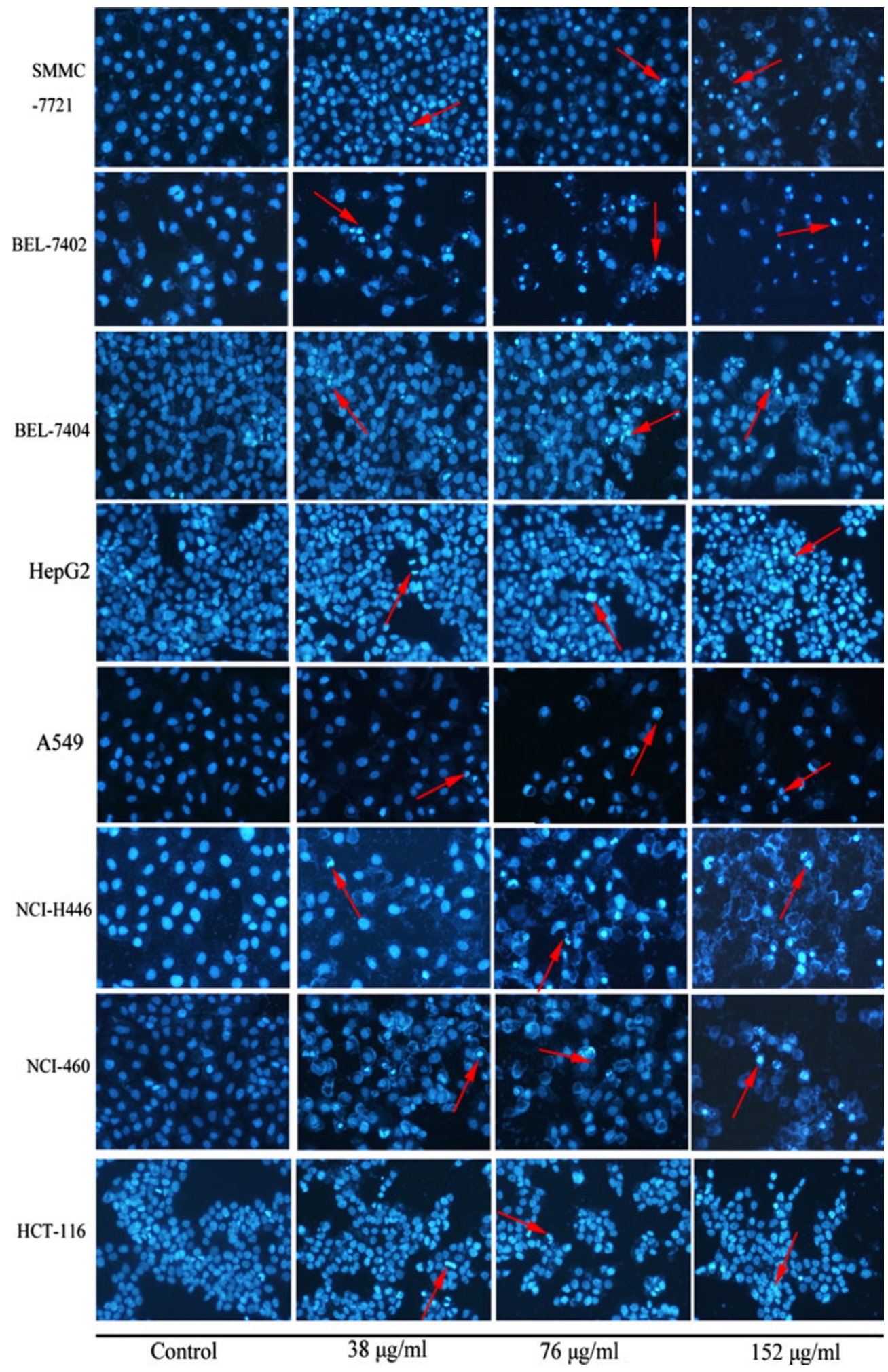

Fig. 5 DAPI staining of the cancer cells treated with different concentrations of $Z J W$ for $24 \mathrm{~h}$. The representative apoptotic bodies were pointed by red arrows 


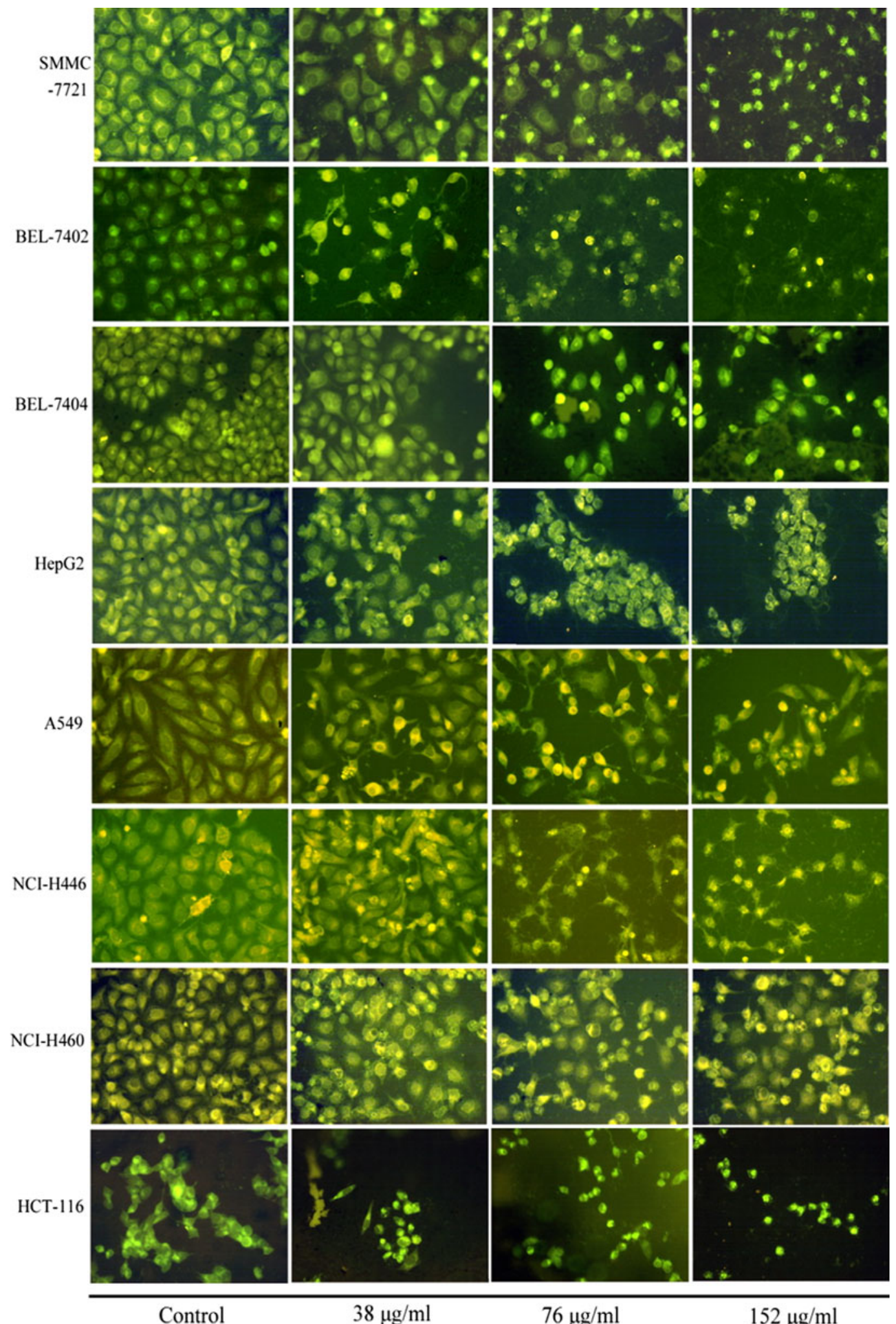

Control

$38 \mu \mathrm{g} / \mathrm{ml}$

$76 \mu \mathrm{g} / \mathrm{ml}$

$152 \mu \mathrm{g} / \mathrm{ml}$

Fig. 6 Rhodamine123 staining of the cancer cells treated with different concentrations of $Z J W$ for $24 \mathrm{~h}$ 


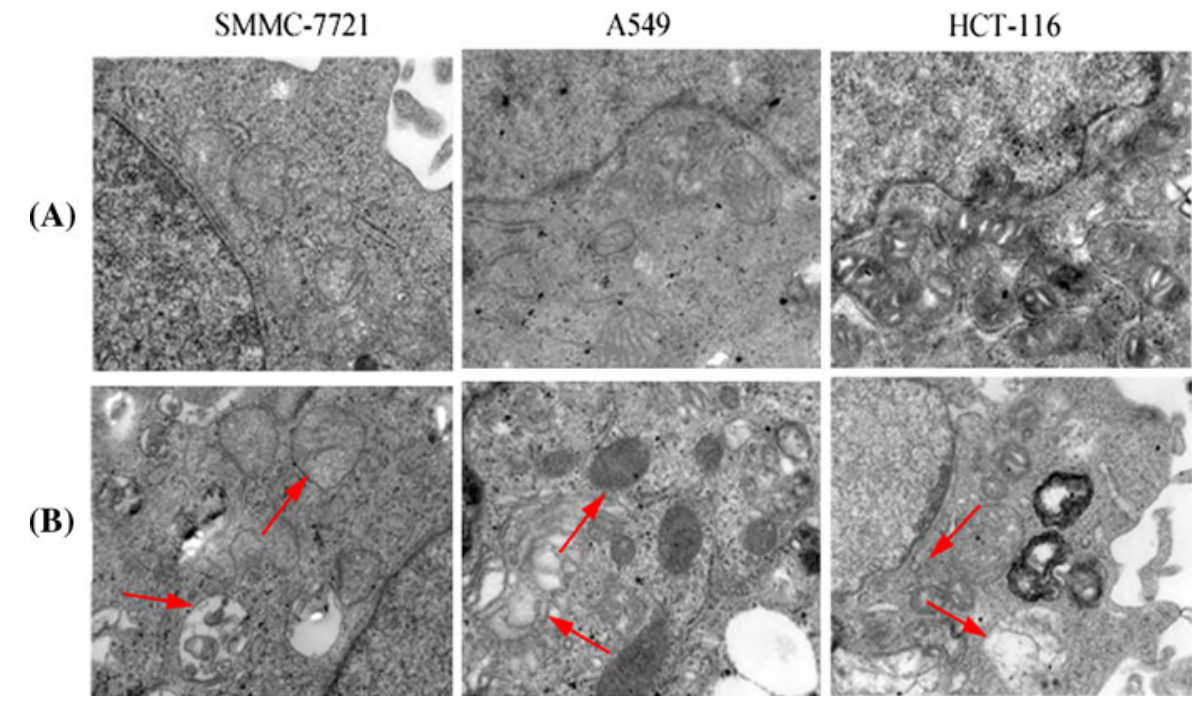

Fig. 7 The ultrastructural changes of SMMC-7721, A549 and HCT-116 cells caused by $Z J W$ were observed by transmission electron microscope analysis $(\times 15,000$, final magnification). (A) Control cells; (B) Cells treated with $152 \mu \mathrm{g} / \mathrm{ml} \mathrm{ZJW}$ for $24 \mathrm{~h}$. In the $Z J W$-treatment group, the mitochondrial double membrane was absent and leaky, distorted cristae were depleted in number, $\mathrm{f}$ vacuoles were present in the cytoplasm and the matrix had a reduced number of electron-dense granules. These representative changes were pointed by red arrows
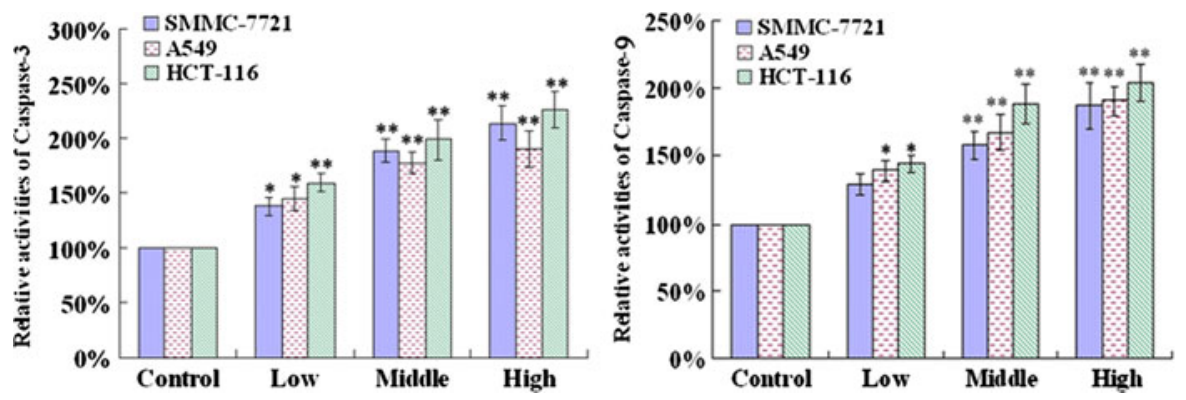

Fig. $8 Z J W$ increases the activities of caspase-3 and -9 in SMMC-7721, A549 and HCT-116 cells. Each value is expressed as mean \pm SEM of three independent experiments. $* p<0.05$ and $* * p<0.01$ significant difference compared with control group

$152 \mu \mathrm{g} / \mathrm{ml}$ of $Z J W$ was chosen as the highest concentration. At the same time, $38 \mu \mathrm{g} / \mathrm{ml}$ and $76 \mu \mathrm{g} / \mathrm{ml}$ of $Z J W$ were selected as the low and medium treatment concentrations, respectively.

Consequently, ZJW caused a dose- dependent decrease in cell numbers compared with the untreated group. The morphological changes that occur in apoptotic cells, like chromatin condensation and nuclear fragmentation were perceived through $\mathrm{AO} /$ EB staining, DAPI staining and TEM assay. This helped in deducing that the cell death that occurred was not due to necrosis, but due to apoptosis. This result was also confirmed by SCGE assay. DNA damage that happened due to apoptosis was pointed out through the distinct comets that formed in the $Z J W$ treated cells.
Moreover, in the flow cytometry study, sub-G1 peaks, which were considered as indicator of cell apoptosis, were clearly observed after the treatment with $Z J W$. These results suggested that these kinds of cancer cells treated with $Z J W$ underwent typical apoptosis.

Apoptosis induced by many natural compounds is closely associated with cell cycle arrest (Yan et al. 2011). Thus, cell cycle regulators could be the target in the treatment and chemoprevention of cancer. Our results indicated that ZJW could arrest SMMC-7721 and HepG2 cells in the G0/G1 phase, and arrest NCI$\mathrm{H} 460$ cells in the $\mathrm{S}$ phase. For the other kinds of cancer cells in our study, no significant cell cycle arrest effects were detected. $Z J W$ is a TCM prescription which is combined with two herbs and multiple constituents. 


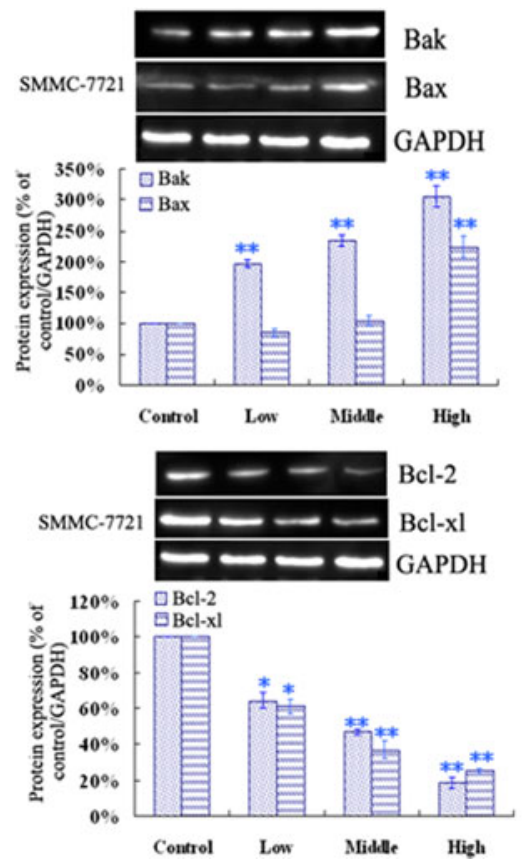

Fig. 9 Western blotting analysis of Bax, Bak, Bcl-2 and Bcl-xl protein expressions in SMMC-7721, A549 and HCT-116 cells. Each value is expressed as mean \pm SEM. Experiment were

This may be the reason for these phenomena. Each herb has its own bioactivities, but when many herbs are combined, there may be changes of bioactivities by synergistic or antagonistic interactions.

The cell surface death receptor (extrinsic) pathway and the mitochondria (intrinsic) pathway (Sprick and Walczak 2004; Letasiova et al. 2005) are two main pathways which are the apoptosis mechanisms occuring in cancer cells. The mitochondria pathway is marked by loss of mitochondrial integrity and activation of caspase-9. The activated caspase- 9 can subsequently activate caspase- 3 , which in turn targets and degrades specific and vital cellular proteins, ultimately resulting in nuclear DNA degradation and apoptotic death of the cells (Sun et al. 2004; Kantari and Walczak 2011; Yan et al. 2011). In our study, the loss of mitochondrial integrity caused by $Z J W$ was found through Rh 123 staining assay. $Z J W$ increased the activities of caspase- 3 and -9 , which suggested that ZJW could activate caspase- 9 via the mitochondriadependent pathway, and then activate the downstream effector, caspase-3, which in turn cleaves the cytoskeleton and nuclear proteins, finally inducing apoptosis.
In the mitochondria pathway, cell apoptosis is regulated by the proteins of the Bcl-2 family. These proteins are involved in positive or negative regulation of apoptotic cell death. Among the anti-apoptotic members, Bcl-2, Bcl-xl, Bcl-w, Bfl-1, Bag-1, Mcl-1, and $\mathrm{A} 1$ are known for protecting against cell death, whereas others, such as Bax, Bak, Blk, Bad, and Bid promote or accelerate cell death. Anti-apoptotic Bcl-2, $\mathrm{Bcl}-\mathrm{xl}$ and pro-apoptotic Bax, Bak are major members of the Bcl-2 family (Lin et al. 2005; Gabriel et al. 2003; Hu et al. 2012). In this study, the expressions of the pro-apoptosis proteins Bax and Bak were upregulated in the cancer cells, and the expressions of the anti-apoptosis proteins Bcl-2 and Bcl-xl were downregulated by $Z J W$. Thus, we can conclude that $Z J W$ might induce SMMC-7721, A549 and HCT-116 cells apoptosis through the activation of mitochondria pathway.

In conclusion, $Z J W$ demonstrates significant cytotoxic activities in SMMC-7721, BEL-7402, BEL7404, HepG2, A549, NCI-H446, NCI-H460 and HCT-116 cells, and the mechanisms relate to its effects on apoptosis. ZJW could induce apoptosis through Caspase-3, -9 and mitochondria pathway. The 
results suggest that $Z J W$ has a therapeutic potential in human hepatocellular carcinoma, lung cancer and colon cancer treatment by suppressing tumor growth, and deserves further study as a potential anti-cancer drug. However, in vivo anticancer effects of $Z J W$, as well as potential molecular mechanisms still need to be further explored.

Acknowledgments This work was supported by Program for New Century Excellent Talents in University (NCET-11-1007), the Program for Liaoning Excellent Talents in University (No. 2009R15) and the Nation Natural Science Foundation of Liaoning Province (No. 201205054).

Conflict of interest There are no financial and commercial conflicts of interest in this study.

\section{References}

Boleti APA, Ventura CA, Justo GZ, Silva RA, Sousa ACT, Ferreira CV, Yano T, Macedo MLR (2008) Pouterin, a novel potential cytotoxic lectin-like protein with apoptosisinducing activity in tumorigenic mammalian cells. Toxicon 51:1321-1330

Can G, Aydiner A (2011) Development and validation of the Nightingale Symptom Assessment Scale (N-SAS) and predictors of the quality of life of the cancer patients in Turkey. Eur J Oncol Nurs 15:3-11

Chao DC, Lin LJ, Kao ST, Huang HC, Chang CS, Liang JA, Wu SL, Hsiang CY, Ho TY (2011) Inhibitory effects of ZuoJin-Wan and its alkaloidal ingredients on activator protein 1 , nuclear factor- $\kappa \mathrm{B}$, and cellular transformation in HepG2 cells. Fitoterapia 82:696-703

Chen YF, Chen WW, Li RL (2003) Effect of Zuojin wan and retro-zuojin wan on inflammatory and protection factors of chills and fever gastric mucosa injury. Chin J Integr Tradit West Med Dig 11:133-135

Cheng DH, Zhao YL, Yang HB (2011) Effect of zuojin pill and fanzuojin pill on the growth metabolism of enterobacteria by microcalorimetry. Zhongguo Zhong Xi Yi Jie He Za Zhi 31:209-212

Dai ZJ, Gao J, Ji ZZ, Wang XJ, Ren HT, Liu XX, Wu WY, Kang HF, Guan HT (2009) Matrine induces apoptosis in gastric carcinoma cells via alteration of Fas/FasL and activation of caspase-3. J Ethnopharmacol 123:91-96

Danhier F, Feron O, Preat V (2010) To exploit the tumor microenvironment: passive and active tumor targeting of nanocarriers for anti-cancer drug delivery. J Control Release 148:135-146

Gabriel B, Sureau F, Casselyn M, Teisie J, Petit PX (2003) Retroactive pathway involving mitochondria in electroloaded cytochrome a-induced apoptosis: protective properties of Bcl-2 and Bcl-xl. Exp Cell Res 289:195-210

Gao X, Yang XW, Marriott PJ (2010) Simultaneous analysis of seven alkaloids in Coptis-Evodia herb couple and Zuojin pill by UPLC with accelerated solvent extraction. J Sep Sci 33:2714-2722

Hu YW, Liu CY, Du CM, Zhang J, Wu WQ, Gu ZL (2009) Induction of apoptosis in human hepatocarcinoma SMMC7721 cells in vitro by flavonoids from Astragalus complanatus. J Ethnopharmacol 123:293-301

Hu M, Xu L, Yin L, Qi Y, Li H, Xu Y, Han X, Peng J, Wan X (2012) Cytotoxicity of dioscin in human gastric carcinoma cells through death receptor and mitochondrial pathways. J Appl Toxicol. doi:10.1002/jat.2715

Jantova S, Cipak L, Letasiova S (2007) Berberine induces apoptosis through a mitochondrial/caspase pathway in human promonocytic U937 cells. Toxicol In Vitro 21: 25-31

Jemal A, Siegel R, Ward E, Hao Y, Xu J, Murray T, Thun MJ (2008) Cancer statistics. CA Cancer J Clin 58:71-96

Kang JX, Liu J, Wang JD, He CW, Li FP (2005) The extract of Huanglian, a medicinal herb, induces cell growth arrest and apoptosis by upregulation of interferon- $\beta$ and TNF- $\alpha$ in human breast cancer cells. Carcinogenesis 26:1934-1939

Kantari C, Walczak H (2011) Caspase-8 and Bid: caught in the act between death receptors and mitochondria. Biochim Biophys Acta (BBA)-Mol. Cell Res 1813:558-563

Kekre N, Griffin C, McNulty J, Pandey S (2005) Pancratistatin causes early activation of caspase-3 and the flipping of phosphatidylserine followed by rapid apoptosis specifically in human lymphoma cells. Cancer Chemother Pharmacol 56:29-38

Letasiova S, Jantova S, Muckova M, Theiszova M (2005) Antiproliferative activity of berberine in vitro and in vivo. Biomed Pap Med Fac Univ Palacky Olomouc Czech Repub 149:461-463

Lin H, Lee YJ, Chen BF, Tsai MC, Lu JL, Chou CJ, Jow GM (2005) Involvement of Bcl-2 family, cytochrome c and caspase- 3 in induction of apoptosis by beauver- icin in human non-small cell lung cancer cells. Cancer Lett 230:248-259

Lu BN, Hu MM, Liu KX, Peng JY (2010a) Cytotoxicity of berberine on human cervical carcinoma HeLa cells through mitochondria, death receptor and MAPK pathways, and in silico drug-target prediction. Toxicol In Vitro 24:1482-1490

Lu CX, Nan KJ, Nie YL, Hai YN, Jiao M (2010b) Delisheng, a Chinese medicinal compound, exerts anti-proliferative and pro-apoptotic effects on HepG2 cells through extrinsic and intrinsic pathways. Mol Biol Rep 37:3407-3412

Pan X, Hartley JM, Hartley JA, White KN, Wang Z, Annie Bligh SW (2012) Evodiamine, a dual catalytic inhibitor of type I and II topoisomerases, exhibits enhanced inhibition against camptothecin resistant cells. Phytomedicine 19:618-624

Pedro C, Pedro ZV, del Eva V, Carlos MC, Pedro SL, Sofia R (2007) Vincristine regulates the phosphorylation of the anti-apoptotic protein HSP27 in breast cancer cells. Cancer Lett 247:273-282

Sheng YX, Zhang JL, Sun SQ (2006) Quality analysis and evaluation of Rhizoma Coptidis under different cultivation conditions. Yao Xue Xue Bao 41:1010-1014

Sun SY, Hail N Jr, Lotan R (2004) Apoptosis as a novel target for cancer chemoprevention. J Nati Cancer Inst 96:662-672

Suresh V, Sruthi V, Padmaja B, Asha VV (2011) In vitro antiinflammatory and anti-cancer activities of Cuscuta reflexa Roxb. J Ethnopharmacol 134:872-877 
Tang J, Feng Y, Tsao S, Wang N, Curtain R, Wang Y (2009) Berberine and Coptidis Rhizoma as novel antineoplastic agents: a review of traditional use and biomedical investigations. J Ethnopharmacol 126:5-17

Wang XN, Han X, Xu LN, Yin LH, Xu YW, Qi Y, Peng JY (2008) Enhancement of apoptosis of human hepatocellular carcinoma SMMC-7721 cells through synergy of berberine and evodiamine. Phytomedicine 15:1062-1068

Wang XN, Xu LN, Peng JY, Liu KX, Zhang LH, Zhang YK (2009) In vivo Inhibition of S180 Tumors by the Synergistic Effect of the Chinese Medicinal Herbs Coptis chinensis and Evodia rutaecarpa. Planta Med 75:1215-1220

Wang S, Penchala S, Prabhu S, Wang J, Huang Y (2010) Molecular basis of traditional Chinese medicine in cancer chemoprevention. Curr Drug Discov Technol 7:67-75
Wang SP, Wu X, Tan M, Gong J, Tan W, Bian BL, Chen MW, Wang YT (2012) Fighting fire with fire: poisonous Chinese herbal medicine for cancer therapy. J Ethnopharmacol 140:33-45

Yan K, Zhang C, Feng J, Hou L, Yan L, Zhou Z, Liu Z, Liu C, Fan Y, Zheng B, Xu Z (2011) Induction of G1 cell cycle arrest and apoptosis by berberine in bladder cancer cells. Eur J Pharmacol 661:1-7

Yang XW, Teng J, Wang Y (2009) The permeability and efflux of alkaloids of Fructus Evodiae in the caco-2 model. Phytother Res 23:56-60

Zhang Y, Zhang S (2008) Inhibition effect of Guizhi-Fulingdecoction on the invasion of human cervical cancer. J Ethnopharmacol 120:25-35 